\title{
Bio-social correlates of intention to use or not to use contraception: The case of Ghana and Nigeria
}

\author{
Christopher Godwin Udomboso ${ }^{a}, b$, A. Y. Amoateng ${ }^{a}$, P. T. \\ Doegah $^{a}$ \\ aSchool of Research and Postgraduate Studies, North-West University \\ (Mafikeng Campus), South Africa

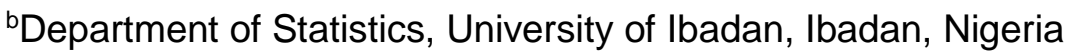

\begin{abstract}
Based on the 2008 and 2013 Demographic and Health Survey data of Ghana and Nigeria respectively, statistical neural network and logit regression models were used to examine the effects of selected bio-social factors on the intention to use contraception among never married and ever married women in the two countries. Results showed that on the whole, the SNN model identified more biosocial factors affecting the intention to use contraception in the two countries than did the logit model. Educational attainment, exposure to media, and visitation to a health facility affected intention to use contraception significantly and positively in both countries. On the other hand, number of living children, infrequent sexual intercourse, postpartum amenorrhea, opposition to contraception and lack of access to contraceptives negatively affected intention to use contraception. The study findings have underscored the rational nature of the decisions women make in using contraception or not.
\end{abstract}

Keywords: Contraception, sub-Saharan Africa, bio-social factors, statistical neural network

\section{Résumé}

Basé sur les données 2008 et 2013 enquête démographique et sanitaire du Ghana et du Nigeria, respectivement, statistique réseau neuronal et modèles de régression logit ont été utilisés pour étudier les effets de certains facteurs biosocial sur l'intention de recourir à la contraception chez les femmes non mariées et mariées dans les deux pays. Les résultats ont montré que dans l'ensemble, le modèle SNN identifié plus de biosocial facteurs influant sur l'intention de recourir à la contraception dans les deux pays que fait la fonction Logit. Niveau de scolarité, exposition aux médias et la fréquentation d'un établissement de santé affecté l'intention d'utiliser la contraception significativement et positivement dans les deux pays. En revanche, nombre d'enfants vivants, rapports sexuels peu fréquents, aménorrhée après l'accouchement, l'opposition à la contraception et le manque 
d'accès aux contraceptifs ont affecté négativement l'intention de recourir à la contraception. Résultats de l'étude actuelle ont mis en évidence le caractère rationnel des décisions des femmes en recourant à la contraception ou pas.

Mots-clés: Contraception, I'Afrique subsaharienne, bio-social des facteurs, statistique réseau neuronal

\section{Introduction}

It has been observed that worldwide $40 \%$ (or $213.4 \mathrm{~m}$ ) of all pregnancies are unintended of which the African continent accounts for $35 \%(53.8 \mathrm{~m})$, with the West African sub-region accounting for $26 \%$ (or $17.6 \mathrm{~m}$ ) (Sedgh, Singh \& Hussain, 20I4) on the African scene. Unintended pregnancies and subsequent childbirth are in turn largely responsible for the prevalence of such other problems such as maternal and child deaths, and ultimately the ill-health of families and nations. According to UNICEF (2009) about 8 million babies die annually before or during delivery or in the first week of life, with many more children becoming motherless yearly. Moreover, these children are 10 times more likely to die within two years of their mothers' death.

According to the same report, regionally Africa has just I $2 \%$ of the global population but accounts for half of all maternal deaths and half the deaths of under-five children, while about 4.7 million mothers, new-borns, and children die each year in sub-Saharan Africa (UNICEF, 2009).

While the above-mentioned problems associated with unintended pregnancies make the use of contraceptives in the developing world, especially, sub-Saharan Africa imperative, the reality is the opposite. For example, currently in subSaharan Africa, the rate of contraceptive usage is $25 \%$. More than half of the countries located in West Africa have a prevalence rate that is about $26 \%$. Ghana and Nigeria, the focus of the present study, have contraceptive usage rates of $23.5 \%$ and $14.1 \%$ respectively (United Nations, 2013).

\section{The Present Study}

It is against this background of high prevalence of unintended pregnancies and low contraceptive use rates in sub-Saharan Africa that we undertake the present study. However, while existing literature on contraceptive usage shows that much has been done in regard to the socioeconomic factors that affect current use of contraception in sub-Saharan Africa, the extant literature is virtually bereft of studies that examine women's intention to use contraception in the future The current study seeks to contribute to the existing body of knowledge on contraceptive use by filling the void in the existing literature by examining the biosocial factors which affect women's intention to use contraception among two groups of women, namely, never married and ever married women in Nigeria and Ghana. We seek to accomplish this goal by using the statistical neural network (SNN) and logit regression models to analyse the 2008 Ghana Demographic and Health Survey and the 2013 Demographic and 
Health Survey (DHS) data for Nigeria respectively.

\section{Review of the Literature}

Number of living children: Many studies have found that women with living children use contraceptives more than their counterparts with no children across various contexts (Nketiah-Amponsah, Arthur, \& Abuosi, 2012; Palamuleni, 2013; Irani, Speizer, \& Fotso, 2014; Rasooly, Ali, Brown, \& Noormal, 2015). However, we do not know how parity affects women's intention to use contraception in the future. Based on what we know from studies on current use of contraception, we posit the following in regard to the effect of number of living children on intention to use contraception:

Hypothesis \# I: The number of living children or parity will negatively affect intention to use of contraception and vice versa regardless of marital status.

. Desire for more children: In Kenya and India, a study of women found no association desire for more children and intention to use contraceptives (Irani et al., 20I4). In the current study, we seek to test the following hypothesis:

Hypothesis \#2: Women who desire to have more children will be less likely than their counterparts who have no desire for more children to use contraception.

Education: Many studies have found no association between level of education attained and current use of contraceptives in various contexts (Agha, 20 I 0; Irani et al., 20I4; Izale, Govender, Fina \& Tumbo, 2014) as well as the intention to use (Grace, 20I0). But other studies in subSaharan African countries and elsewhere have found positive and significant associations between education and both current and future contraceptive use (e.g. Rasooly et al., 2015Okezie, Ogbe \& Okezie 2010; Nketiah-Amponsah et al., 20I2; Tekelab, Sufa \& Wirtu, 20I5), while others have found negative relationships between education and contraceptive use (e.g. Okech et al., 20 I I; Sharma, Pratap \& Ghimire, 20I I). Education equips women with knowledge about the effects of unintended pregnancy both for successful completion of their education which also affects the quality of the children they have. In view of this role of education, we will test the following hypothesis:

Hypothesis \#3: Women who attain high education will be more likely than those with low educational attainment to indicate intention to use contraceptives, regardless of marital status.

Region of residence: In their study, Omondi and Ayiemba (2004) found a strong differential influence between region of residence and intention to use contraception. They observed that region of residence had a direct link with cultural as well as traditional influences on reproductive behavioural characteristics, while low rates of contraceptive use was associated with regions where women had characteristics such as low education, limited formal-sector employment and limited access to outlets for health and family planning. In the current study, we seek to test the following hypothesis:

Hypothesis \#4: In the present study, we hypothesise that region of residence will be associated with the intention to use contraceptives irrespective of the level of such contextual characteristics as 
education, employment availability, amenities etc.

Place of residence: The results of empirical studies on the effect of place of residence on contraceptive usage are at best mixed. For example, studies conducted in Nepal, Guatemala, as well as some 26 African countries found no association between rural or urban place of residence and contraceptive use (Sharma et al., 20II; Grace, 2010; Longwe, Huisman. \& Smith 20I2). However, Rasooly et al (20/5) found higher proportion of current users of contraception among women who resided in rural areas compared to their counterparts who resided in urban areas. However, studies in Ghana and Malawi found low contraceptive usage among rural women (Nketiah-Amponsah et al., 2012; Palamuleni, 2013) Because of the inequitable distribution of these amenities between rural and urban areas, in the present study we posit that:

Hypothesis \#5: Women in rural areas will be less inclined to use contraceptives compared to their counterparts in urban areas regardless of marital status.

Religion: A woman's religious affiliation has been observed to significantly predict her use of contraception (NketiahAmponsah et al., 20I2; lzale et al., 20I4), while religion was found to negatively affect a woman's use of contraception in Delhi and the urban slums of Kenya ( Abdulla 20l4; Rustagi, Taneja, Kaur \& Ingle, 20I0; Okech et al., 20II). Because of ideological and doctrinal differences, in the current study, we posit that:

Hypothesis \#6: Religious affiliation will be predictive of intention to use contraception.
Media exposure: Exposure to the media was found to be associated significantly with the current use of contraceptives in a study among women in countries such as India, rural Haryana, Nigeria, Taiwan, Nepal and some other 26 African countries and Afghanistan (Longwe et al., 2012; Rasooly et al., 2015; Okezie et al., 2010; Cheng 20II; Sharma et al., 20II). Even though like many of the factors under investigation in the current study, not much is known empirically about its effect on future use of contraceptives, we posit that:

Hypothesis \#7: Women who are exposed to the mass media will be more inclined than their counterparts who have no exposure to the media to use contraceptives.

Ethnicity. Ethnicity reflects cultural traditions and practices and thus affects family-related behaviours like the use of contraception. For example, African Americans in the United States have been found to be non-users of contraceptives in comparison to their white counterparts (Frost, Singh \& Finer, 2007). In some African countries, variations have been found in the use of contraceptives with regards to ethnicity (Odimegwu 1999; Izale et al. 20/4). To the extent that ethnicity reflects cultural beliefs and practices, we posit in the current study that:

Hypothesis \#8: Ethnicity will be associated with intention to use contraception in Ghana and Nigeria regardless of marital status.

Visitation by a health worker. In Nepal, visitation from a health worker was found to influence women in current contraceptive use (Sharma et al., 20II), 
while it was found to have positive effect on Bangladeshi women's intention to use contraceptives (Islam et al., 1998). In the present study we posit that:

Hypothesis \#9: Women who are visited by health worker will be more inclined to use contraception compared to their counterparts who do not get visits from a health worker.

Visitation to a health facility. While no association was found between visitation to a health facility and intention to use contraception among women in Bangladesh (Islam et al., 1998), in Malawi the relationship was positive (Palamuleni, 20I3). Because of the exposure to information which a visit to a health facility might engender, in the current study we posit that:

Hypothesis \# 10: Women who visit a health facility will be more inclined than their counterparts who do not visit a health facility to use contraceptives.

Coital frequency. Infrequent sex was found to be positively associated with nonuse of contraceptives among women in Honduras, Peru, Armenia, Egypt and Morocco (Sedgh, Hussain, Bankole \& Singh 2007). Because of the positive association between coital frequency and conception, in the current study, we posit that:

Hypothesis \#II: Women who have infrequent sex with their partners will be less inclined to use contraceptives than their counterparts who have frequent sexual intercourse with their partners.

Subfecundity. A study of women in Morocco and Zambia found that those who considered themselves to be infecund or sub-fecund reported non-use of contraceptives (Sedgh et al., 2007). Also, infecundity was reported as a reason for women in Indian who had no intention of using contraceptives in the future (Mishra et al., 1999). Because of this biological condition of inability to conceive, in the present study we posit that:

Hypothesis \# 12: Women who know that they are infecund or unable to conceive will be less inclined to use contraceptives in the future compared to women who are fecund, regardless of marital status.

Postpartum amenorrhea: In studies in the Congo, Guinea, Kenya, Malawi, Mozambique, Rwanda, Senegal, Zambia and Nepal women who regarded themselves to be experiencing postpartum amenorrhea were observed to be nonusers of contraceptives (Sedgh et al., 2007). As far as future use of contraceptives by women who have postpartum amenorrhea is concerned, we posit that:

Hypothesis \#13: Women who experience postpartum amenorrhea will be less inclined to use contraceptives compared to their counterparts who do not experience postpartum amenorrhea.

Opposition to use: In studies of countries as diverse as Chad, Guinea, Mauritania, Nigeria, Ghana, Malawi, India, and a few others, it was observed that women who were faced with opposition to the use of contraceptives from significant others (e.g. self, husband or partner, religious affiliation, and others from family, neighbourhood, friends and acquaintances, etc.) were less likely to use contraceptives (e.g. Sedgh et al. 2007; Rustagi et al. 2010; Palamuleni. 2013). In the current study, we posit that:

Hypothesis \# 14: Women who face opposition to use contraceptive from their 
significant others will be less inclined to use contraceptives compared to women who do not face such opposition.

Cost of contraceptives: Cost of contraceptives was found not to be a major barrier to use of contraception in a study conducted in some African countries, but that was not the case among women in Burkina Faso where it was found to be a main obstacle (Sedgh et al., 2007). Among women in Pakistan, access to contraceptives was equally found to determine the increased use of contraceptives among women in Pakistan (Mahmood \& Ringheim, 1996). In the present study, we expect the following relationship between cost of contraceptives and intention to use contraception:

Hypothesis \# 15: Women who are unable to afford to buy contraceptives or are physically unable to access contraceptives will be less inclined to use contraceptives and vice versa.

Fear of side effects: In the case of fear of side effects, it has been observed to influence use of contraception. A study among women in Delhi, India, reported side effects as the main reason for nonusage of contraceptives (Rustagi et al., 20/0). In the current study, we expect the following relationship between fear of side effects and intention to use contraception:

Hypothesis \#16: Women who fear side effects of contraceptives will be less likely to indicate intention to use contraceptives compared to women who do not fear side effects.

\footnotetext{
1 The variables, infecundity/subfecundity and lack of access to contraception were dropped
}

\section{Data and Methods}

The data for the present study come from the most recent female files of the Demographic and Health Surveys (DHS) for Ghana in 2008 and Nigeria in 2013 respectively. A total of 38949 females participated in the Nigeria survey, while 4917 females participated in the Ghana survey. For the present analysis all missing observations were deleted. This resulted in effective sample sizes of 9680 and 1803 females for Nigeria and Ghana respectively'. The analysis for the present study is limited to women who are single and never married (653 and 377 in Nigeria and Ghana respectively) and ever married women (9027 and 1426 in Nigeria and Ghana respectively). The dependent variable is intention to use contraception.

\section{Measures of Variables}

The dependent variable, intention to use contraception, was measured as $0=$ 'intention not to use contraception' and I $=$ 'intention to use contraception'. As far as the independent variables are concerned, number of living children was measured as the exact number of natural living children born to each woman. Desire for more children was measured as $1=$ 'Wants within 2 years', 2 = 'Wants after $2+$ years', $3=$ 'Wants, unsure timing', $4=$ 'Undecided', $5=$ 'Wants no more', $6=$ 'Sterilized (respondent or partner)', $7=$ 'Declared infecund', and $8=$ 'Never had sex'. Education was measured as $0=$ 'No education', I = 'Primary', 2 = 'Secondary', 3 = 'Higher'.

for the never married category in Ghana. This was due to the lack of variation in the data set. 
In Nigeria, a region refers to a geographical zone that groups some states (which are secondary level of administration in the country) together, while in Ghana, a region is a secondary level of administration in the country. Thus, region of residence in Nigeria was measured as $\mathrm{I}=$ 'North Central', $2=$ 'North East', 3 = 'North West', 4 = 'South East', 5 = 'South South', and 6 = 'South West'. And in Ghana, region of residence was measured as I = 'Western', $2=$ 'Central', 3 = 'Greater Accra', 4 = 'Volta', $5=$ 'Eastern', $6=$ 'Ashanti', $7=$ 'Brong Ahafo', 8 = 'Northern', 9 = 'Upper East', and $10=$ 'Upper West'.

Place of residence was measured as I = 'Urban' and 2 = 'Rural'. The variable religion had different coding in the two countries. In Nigeria, it was measured as 0 = 'Other', I = 'Catholic', 2 = 'Other Christian', 3 = 'Islam', and $4=$ 'Traditionalist', while in Ghana, it was measured as $0=$ 'Other', I = 'Catholic', 2 $=$ 'Anglican', $3=$ 'Methodist', $4=$ 'Presbyterian', $5=$ 'Pentecostal/Charismatic', $6=$ 'Other Christian', 7 = 'Moslem', $8=$ 'Traditional/spiritualist', and $9=$ 'No religion'. Media exposure was a summated measure of exposure to radio, $\mathrm{TV}$, and newspaper, and was measured as $0=$ 'No' and I = 'Yes'.

Ethnicity also had different categories in the two countries. In Nigeria, the measure was $\mathrm{I}=$ 'Hausa', 2 = 'Yoruba', 3 = 'Igbo/lbo', $4=$ 'Fulani', $5=$ 'Kanuri/Beriberi', 6 = 'Ibibio', 7 = 'Efik', 8 = 'Tiv', 9 = 'ljaw (Izon)', $10=$ 'Bini/Edo', I I = 'Nupe', I 2 = 'Urhobo', I 3 = 'Igala', $14=$ 'Idoma', $15=$ 'Esan', and $16=$ 'Other'. In Ghana, ethnicity was measured as $\mathrm{I}=$ 'Akan', $2=$ 'Ga/Dangme', $3=$ 'Ewe', 4 = 'Guan', 5 = 'Mole-Dagbani', 6 = 'Grussi', $7=$ 'Gruma', $8=$ 'Mande', and $10=$ 'Other'. The following variables; visited by a health worker, visited a health centre, infrequent sex, infecund/subfecund, and postpartum amenorrhea were measured as $0=$ 'No' and I = 'Yes'.

The variable opposition to use was a summated measure of respondent opposed, partner opposed, others opposed, religious prohibition, and was measured as $0=$ 'No' and I = 'Yes'. Finally the variables cost of contraceptives, lack of access to contraceptives, and fear of side effects were also measured as $0=$ 'No' and I = 'Yes'. These were responses to the question: 'You have said that you do not want any (more) children, can you tell me why you are not using a method (of contraception) to prevent pregnancy? The responses to the variables, in fecund/sub fecund and access to contraceptives were the same across the cases. For both variables, the responses were "No". They were therefore dropped in the analysis of the category since they are singular or "illconditioned". That is, their determinants are zeroes, and hence do not have inverses.

\section{Statistical Approach}

The study uses the exploratory data analysis (EDA), bivariate analysis, and the multivariate analysis. With the EDA summary of the main characteristics are computed. For the bivariate analysis the Spearman's Rank Correlation (Association) Coefficient was used. For the multivariate analysis, we used the logit regression and 
SNN models. All tests are evaluated at the $5 \%$ level of significance.

\section{Logit Model}

The logit model is given as

$$
\begin{gathered}
\operatorname{logit} p(x)=\log \frac{p(x)}{1-p(x)}=\log \frac{p(x)}{q(x)} \\
=\alpha+\beta x
\end{gathered}
$$

where $x$ is a factor affecting intention to use contraception, $p(x)$ is the probability of intention to use contraception for a given value of $x, q(x)$ is the complement of the probability of intention to use contraception, $\beta$ is the coefficient of the given value of $x$, and $\alpha$ is the constant coefficient.

\section{Statistical Neural Network}

We use the SNN model in this study to analyze the impact of the bio-social factors on future contraceptive usage. The choice of neural networks is motivated by its flexibility and power of estimation compared to other statistical methods. SNN has been found to be powerful in estimating imprecise and noisy (meaningless, corrupt) data set, or any data that cannot be understood and interpreted correctly. It has been found applicable in all fields that use data, both qualitative and quantitative.

The simple model used is as proposed by Anders (1996).

$y=\alpha \mathbf{X}+\sum_{h=1}^{H} \beta_{h} g\left(\sum_{i=0}^{I} \gamma_{h i} \mathbf{X}_{i}\right)+e_{i}$

where $y$ is the intention to use contraception; $\mathbf{X}=\left(\mathrm{x}_{0}, \mathrm{x}_{1}, \ldots, \mathrm{x}_{1}\right)$ are the factors affecting intention to use contraception, with $\mathbf{x}_{0} \equiv 1, \mathbf{W}=(\alpha, \beta, \gamma)$ are the weights of the network attached to the input layer, hidden layer and the transfer function respectively; $e_{i}$ is the noise normally distributed with mean 0 and variance $\sigma^{2} ; g($.$) is the transfer function;$ $h=1,2, \ldots, H$ is the number of hidden units; $i=0,1, \ldots I$ is the number of input units.

Udomboso (2014) established the estimates of the parameters as follows:

$\widehat{\boldsymbol{\alpha}}=\frac{\sum_{i=1}^{n} \boldsymbol{y}_{i}^{*} \boldsymbol{h}_{i(\alpha)}}{\sum_{i=1}^{n} \boldsymbol{h}_{i(\alpha)}^{2}}$

$\widehat{\boldsymbol{\beta}}=\frac{\sum_{i=1}^{n} \boldsymbol{y}_{\boldsymbol{i}}^{*} \boldsymbol{h}_{\boldsymbol{i}(\boldsymbol{\beta})}}{\sum_{i=1}^{\boldsymbol{n}} \boldsymbol{h}_{\boldsymbol{i}(\boldsymbol{\beta})}^{\mathbf{2}}}$

$\widehat{\gamma}=\frac{\sum_{i=1}^{n} \boldsymbol{y}_{i}^{*} \boldsymbol{h}_{i(\gamma)}}{\sum_{i=1}^{n} \boldsymbol{h}_{i(\gamma)}^{2}}$

This study uses fifteen hidden neurons, namely; I to 5 , and 10 to 100 . Hidden neurons are abstract variable separation nodes that separate variables coming from the input unit before the transfer functions maps the variables to the output unit. The higher the number of hidden neurons, the wider the separations, and the more precise the mapping to the output unit. The mean square error (MSE), which measures the average of the squares of the errors generated in an estimation procedure, the network information criterion (NIC) which is a measure of the relative quality of the SNN model for a given set of data, are used in model selection. The coefficient of determination $\left(R^{2}\right)$, which is a number that indicates how 
well a set of data fit a statistical model is used in determining the goodness of fit of the models. The significance of the model is determined by computing the Fisher statistic, $F$, and its $p$-value. The model with the least MSE, or NIC is considered as the best; this coincides with the model with the highest $R^{2}$.

\section{Results}

Table I shows the percentage distributions of the background characteristics of the respondents in both countries. The table shows that $49 \%$ and $59 \%$ of never married women indicated their intention to use contraception in the future in Nigeria and Ghana respectively. On the other hand, $27 \%$ and $47 \%$ of ever married women indicated their intention to use contraception in the future in Nigeria and Ghana respectively. In terms of number of children, $83 \%$ and $84 \%$ of single women in Nigeria and Ghana respectively have no children, while only $1 \%$ of ever married women in both countries have no children. As far as educational attainment goes, while $12 \%$ of never married women in Nigeria have post-secondary education, the same is true of only $3 \%$ of their counterparts in Ghana; $4 \%$ and $6 \%$ of never married women in Nigeria and
Ghana respectively do not have formal education.

On the other hand, $5 \%$ of the ever married women in Nigeria have higher education compared to only $2 \%$ of their counterparts in Ghana; $47 \%$ and $39 \%$ of ever married women in Nigeria and Ghana respectively have no formal education. Thirty-one percent and 32\% of never married women in Nigeria and Ghana respectively have had exposure to the media, while $15 \%$ and $32 \%$ of the ever married women in Nigeria and Ghana respectively have had exposure to the media. Five percent and $7 \%$ of never married women in Nigeria and Ghana respectively reported visitation by a health worker compared to $10 \%$ and $14 \%$ in Nigeria and Ghana respectively among the ever married women. In terms of opposition to the use of contraception, only $1 \%$ of the never married women in Nigeria report any opposition to the use of contraception compared to $5 \%$ of their ever married counterparts; in Ghana while none of the single women reported any form of opposition to contraceptive use, only $1 \%$ of their ever married counterparts reported some form of opposition to contraceptive use. 
African Population Studies Vol. 29, No. 2, Supplement, 2015

Table I: $\quad$ Percentage distributions of the study variables

\begin{tabular}{|c|c|c|c|c|c|}
\hline \multirow[t]{2}{*}{ Variable } & \multirow[t]{2}{*}{ Measures } & \multicolumn{2}{|c|}{ Never Married } & \multicolumn{2}{|c|}{ Ever Married } \\
\hline & & Nigeria & Ghana & Nigeria & Ghana \\
\hline Intention to use & Intention to use & 49 & 59 & 27 & 47 \\
\hline Contraception & Intention not to use & 51 & 41 & 73 & 53 \\
\hline \multirow[t]{5}{*}{ Number of living children } & No child & 83 & 84 & 1 & 1 \\
\hline & I to 3 children & 16 & 15 & 43 & 51 \\
\hline & 4 to 6 children & I & I & 41 & 39 \\
\hline & 7 to 10 children & - & - & 14 & 8 \\
\hline & II to I4 children & - & - & I & 1 \\
\hline \multirow[t]{2}{*}{ Desire for more children } & Wants after $2+$ years & 96 & 97 & 58 & 46 \\
\hline & Wants no more & 4 & 3 & 42 & 54 \\
\hline \multirow[t]{4}{*}{ Education } & No education & 4 & 6 & 47 & 39 \\
\hline & Primary & 8 & 17 & 24 & 23 \\
\hline & Secondary & 76 & 74 & 24 & 36 \\
\hline & Higher & 12 & 3 & 5 & 2 \\
\hline \multirow[t]{2}{*}{ Media exposure } & Yes & 31 & 32 & 15 & 31 \\
\hline & No & 69 & 68 & 85 & 69 \\
\hline \multirow{2}{*}{$\begin{array}{l}\text { Visitation by a health } \\
\text { worker }\end{array}$} & Yes & 5 & 7 & 10 & 14 \\
\hline & No & 95 & 93 & 90 & 86 \\
\hline \multirow[t]{2}{*}{ Opposition to use } & Yes & 1 & 0 & 5 & 1 \\
\hline & No & 99 & 100 & 95 & 99 \\
\hline \multirow[t]{2}{*}{ Fear of side effects } & Yes & 3 & 9 & 10 & 21 \\
\hline & No & 97 & 91 & 90 & 79 \\
\hline
\end{tabular}

"Nigeria; \# Ghana.

Tables 2 to 4 show the results of the bivariate analyses. In table 2 , the results of the Spearman's rank associations of the biosocial factors with the intention to use contraceptives are shown for each country. Even though all the bio-social factors are generally weakly associated with intention to use contraceptives in both countries, in Nigeria, all the factors are significantly associated with intention to use contraceptives at both $1 \%$ and $5 \%$ levels with the exception of fear of side effects. The factors that are significantly positively associated with intention to use contraceptives in both countries are education, visitation to a health facility, infrequent sex, and postpartum amenorrhea. On the other hand, the factors that are significantly negatively associated with intention to use contraception in the two countries are number of living children, desire for more children and infecundity. 
Table 2: Spearman's Correlation Coefficient between Biosocial Factors and Intention to use Contraception

\begin{tabular}{|l|l|l|}
\hline Independent variables & \multicolumn{1}{|c|}{ Nigeria } & \multicolumn{1}{c|}{ Ghana } \\
\hline Number of living children & $-0.132^{* *}$ & $-0.137^{* *}$ \\
\hline Desire for more children & $-0.107^{* *}$ & $-0.259^{* *}$ \\
\hline Education & $0.276^{* *}$ & $0.082^{* *}$ \\
\hline Region of residence & $0.074^{* *}$ & 0.011 \\
\hline Place of residence & $-0.100^{* *}$ & 0.045 \\
\hline Religion & $-0.219^{* *}$ & -0.024 \\
\hline Media exposure & $0.155^{* *}$ & 0.038 \\
\hline Ethnicity & $0.112^{* *}$ & -0.023 \\
\hline Visitation by a health worker & $0.194^{* *}$ & 0.031 \\
\hline Visitation to a health facility & $0.206^{* *}$ & $0.156^{* *}$ \\
\hline Infrequent sex & $0.086^{* *}$ & $0.063^{* *}$ \\
\hline Infecundity/Subfecundity & $-0.055^{* *}$ & $-0.081^{* *}$ \\
\hline Postpartum amenorrhea & $0.108^{* *}$ & $0.120^{* *}$ \\
\hline Opposition to use & $-0.095^{* *}$ & -0.023 \\
\hline Cost of contraceptives & $0.056^{* *}$ & 0.037 \\
\hline Access to Contraception & $0.044^{* *}$ & 0.027 \\
\hline Fear of side effects & $0.023^{*}$ & -0.073 \\
\hline
\end{tabular}

${ }^{*}$ Significant at $5 \%$ level of significance (2-tailed)

${ }^{* *}$ Significant at $1 \%$ level of significance (2-tailed)

Table 3 shows the Spearman's rank associations of the biosocial factors with intention to use contraception. Among the never married women in both Ghana and Nigeria, the factors that are positively associated with intention to use contraception are media exposure, visitation to a health facility, and education (at the $1 \%$ level in Nigeria). The factors that are negatively associated with intention to use contraception in Nigeria include desire for more children and opposition to use of contraception, while in Ghana desire for more children is the only factor. As far as ever married women in Nigeria are concerned, all the bio-social factors are significantly associated with intention to use contraceptives at both $1 \%$ and $5 \%$ levels, except number of living children, desire for more children, place of residence, religion, infecundity/ subfecundity, and opposition to use of contraception which are negatively associated with intention to use contraceptives among ever married women in Nigeria. However, among ever married women in Ghana, infrequent sex and cost of contraceptives are the only two factors that are significantly and positively associated with intention to use contraceptives at the $5 \%$ level, while significant negative association is found for only fear of side effects. 
African Population Studies Vol. 29, No. 2, Supplement, 2015

Table 3: Spearman's Correlation Coefficient between Biosocial Factors and Intention to use Contraception among the Never Married and the Ever Married Women

\begin{tabular}{|l|c|c|c|c|}
\hline \multirow{2}{*}{ Independent variables } & \multicolumn{2}{|c|}{ Never Married } & \multicolumn{2}{c|}{ Ever Married } \\
\cline { 2 - 5 } & Nigeria & Ghana & Nigeria & Ghana \\
\hline Number of living children & 0.045 & 0.025 & $-0.095^{* *}$ & $-0.121^{* *}$ \\
\hline Desire for more children & $-0.131^{* *}$ & $-0.111^{*}$ & $-0.085^{* *}$ & $-0.268^{* *}$ \\
\hline Education & $0.132^{* *}$ & $0.150^{* *}$ & $0.263^{* *}$ & 0.040 \\
\hline Region of residence & 0.013 & -0.092 & $0.056^{* *}$ & 0.043 \\
\hline Place of residence & -0.050 & 0.012 & $-0.087^{* *}$ & $0.075^{* *}$ \\
\hline Religion & -0.068 & -0.080 & $-0.213^{* *}$ & 0.002 \\
\hline Media exposure & $0.080^{*}$ & $0.108^{*}$ & $0.151^{* *}$ & 0.019 \\
\hline Ethnicity & -0.029 & -0.097 & $0.113^{* *}$ & 0.002 \\
\hline Visitation by a health worker & 0.061 & -0.007 & $0.211^{* *}$ & 0.048 \\
\hline Visitation to a health facility & $0.090^{*}$ & 0.075 & $0.221^{* *}$ & $0.201^{* *}$ \\
\hline Infrequent sex & 0.042 & 0.071 & $0.090^{* *}$ & $0.061^{*}$ \\
\hline Infecundity/Subfecundity & -0.038 & & $-0.052^{* *}$ & $-0.083^{* *}$ \\
\hline Postpartum amenorrhea & 0.002 & 0.043 & $0.123^{* *}$ & $0.140^{* *}$ \\
\hline Opposition to use & $-0.101^{* *}$ & & $-0.091^{* *}$ & -0.023 \\
\hline Cost of contraceptives & 0.055 & -0.071 & $0.060^{* *}$ & $0.060^{*}$ \\
\hline Access to Contraception & 0.014 & -0.104 & $0.032^{* *}$ & $-0.055^{*}$ \\
\hline Fear of side effects & & & $0.053^{* *}$ & 0.034 \\
\hline Significant at 5\% leve & & & & \\
\hline
\end{tabular}

* Significant at $5 \%$ level of significance (2-tailed)

** Significant at $1 \%$ level of significance (2-tailed)

Table $4 \mathrm{a}$ shows the results for the model determination of the statistical neural network, while table $4 \mathrm{~b}$ shows the results of the comparison of the multivariate analysis using the SNN and the logit models. Table 4a shows that among both never married and ever married women, the SNN models with 100 hidden neurons ( $\mathrm{HNs}$ ) are appropriate for each of the two countries ${ }^{2}$. This means a 100

\footnotetext{
${ }^{2}$ This is because they have the least MSEs and

NICs, as well as corresponding high $\mathrm{R}^{2}$, as the case may be.
} 
variables separation nodes are needed to separate the factors affecting intention to use contraception so as to a wider coverage for the transfer functions to map the variables to the output unit. Table $4 \mathrm{~b}$ shows that among the never married women in Nigeria, the logit regression could not compute results for infecundity/subfecundity, opposition to use contraception, and lack access to contraception, while in Ghana, it could not compute results for infecundity/subfecundity, lack of access to contraception, postpartum amenorrhea and opposition to use of contraception.

But among never married in Nigeria, both models show that only education has significantly positive impact on the intention to use contraceptives, while the desire for more children and opposition to use of contraception have significantly negative impact on the intention to use contraceptives. In Ghana however, both models show that education and media exposure have significantly positive impact on the intention to use contraception among never married women. Also in Ghana, the SNN shows that place of residence has significantly positive impact on the intention to use contraception, while the logit model shows that number of living children has significantly positive impact on the intention to use contraception.

Among the ever married women in both countries, both SNN and Logit models show that education, media exposure, ethnicity, visitation by a health worker, visitation to a health facility, infrequent sex, postpartum amenorrhea, cost of contraceptives, and lack of access to contraception have significantly positive impact on the intention to use contraception; the SNN model shows that in Nigeria, the number of living children, region of residence, and place of residence uniquely impact significantly and positively on the intention to use contraception. As far as the negative impact on intention to use contraception is concerned the factors that are common to both countries include desire for more children, condition of infecundity/subfecundity, religion, and opposition to use of contraception have significantly negative impact on the intention to use contraception; fear of side effects is unique to ever married women in Ghana. 
African Population Studies Vol. 29, No. 2, Supplement, 2015

Table 4a: Statistics of Model Determination

\begin{tabular}{|c|c|c|c|c|c|c|c|c|c|c|c|c|}
\hline \multirow{3}{*}{$\begin{array}{l}\text { Hidden } \\
\text { Neuron }\end{array}$} & \multicolumn{6}{|c|}{ Never Married } & \multicolumn{6}{|c|}{ Ever Married } \\
\hline & \multicolumn{2}{|c|}{ MSE } & \multicolumn{2}{|c|}{$\mathbf{R}^{2}$} & \multicolumn{2}{|c|}{ NIC } & \multicolumn{2}{|c|}{ MSE } & \multicolumn{2}{|c|}{$\mathbf{R}^{2}$} & \multicolumn{2}{|c|}{ NIC } \\
\hline & Nigeria & Ghana & Nigeria & Ghana & Nigeria & Ghana & Nigeria & Ghana & Nigeria & Ghana & Nigeria & Ghana \\
\hline 1 & 0.253 & 0.252 & 0.02 & 0.00 & 0.259 & 0.284 & 0.196 & 0.253 & 0.00 & 0.00 & 0.203 & 0.204 \\
\hline $5^{*(*)(+)}$ & 0.240 & 0.252 & 0.07 & 0.00 & 0.237 & 0.295 & 0.175 & 0.238 & 0.10 & 0.06 & 0.176 & 0.236 \\
\hline $10^{+(*)(+)}$ & 0.251 & 0.231 & 0.03 & 0.09 & 0.259 & 0.236 & 0.167 & 0.226 & 0.15 & 0.11 & 0.165 & 0.228 \\
\hline $25^{*+(*)}(+)$ & 0.237 & 0.126 & 0.08 & 0.50 & 0.234 & 0.127 & 0.18 & 0.221 & 0.08 & 0.12 & 0.180 & 0.224 \\
\hline $50^{*(*)(+)}$ & 0.215 & 0.245 & 0.16 & 0.03 & 0.213 & 0.252 & 0.142 & 0.138 & 0.27 & 0.45 & 0.142 & 0.139 \\
\hline $75^{*+(*)(+)}$ & 0.059 & 0.206 & 0.77 & 0.19 & 0.060 & 0.203 & 0.089 & 0.109 & 0.55 & 0.57 & 0.089 & 0.110 \\
\hline $100^{*}+\left({ }^{*}\right)(+)$ & $0.008^{* *}$ & $0.081^{* *}$ & 0.97 & 0.68 & 0.009 & 0.079 & $0.007^{* *}$ & $0.106^{* *}$ & 0.96 & 0.58 & 0.008 & 0.106 \\
\hline
\end{tabular}

** Model selected for prediction

* Significant at $5 \%$ level of significance $(P>F)$ for Nigeria (never married) + Significant at $5 \%$ level of significance $(P>F)$ for Ghana $($ never married)

(*) Significant at $5 \%$ level of significance $(P>F)$ for Nigeria (ever married)

${ }^{(+)}$Significant at $5 \%$ level of significance $(P>F)$ for Ghana (ever married) 
Table 4b: Estimates of the Biosocial Factors affecting Intention to use Contraception among the Never Married and Ever Married Women in Nigeria and Ghana

\begin{tabular}{|c|c|c|c|c|c|c|c|c|}
\hline \multirow[t]{3}{*}{ Independent variables } & \multicolumn{4}{|c|}{ Never Married } & \multicolumn{4}{|c|}{ Ever Married } \\
\hline & \multicolumn{2}{|c|}{ Nigeria } & \multicolumn{2}{|c|}{ Ghana } & \multicolumn{2}{|c|}{ Nigeria } & \multicolumn{2}{|c|}{ Ghana } \\
\hline & $\beta$ & OR & $\boldsymbol{\beta}$ & OR & $\beta$ & OR & $\beta$ & OR \\
\hline Number of living children & 0.06 & 1.32 & 0.08 & $1.77^{*}$ & $0.01^{*}$ & 1.02 & 0.01 & 1.05 \\
\hline Desire for more children & $-0.07^{*}$ & $0.50^{*}$ & -0.05 & $0.49^{*}$ & $-0.03^{*}$ & $0.80^{*}$ & $-0.06^{*}$ & $0.68^{*}$ \\
\hline Education & $0.16^{*}$ & $1.50^{*}$ & $0.18^{*}$ & $1.57^{*}$ & $0.09^{*}$ & $1.40^{*}$ & $0.07^{*}$ & 1.11 \\
\hline Region of residence & 0.02 & 0.99 & 0.01 & 1.00 & $0.01^{*}$ & 0.97 & 0.01 & 1.01 \\
\hline Place of residence & 0.08 & 0.86 & $0.17^{*}$ & 1.51 & $0.07^{*}$ & 0.96 & $0.19^{*}$ & $1.48^{*}$ \\
\hline Religion & 0.03 & 0.80 & -0.00 & 0.94 & 0.00 & $0.67^{*}$ & $0.02^{*}$ & 1.01 \\
\hline Media exposure & 0.10 & 1.23 & $0.22^{*}$ & $1.71^{*}$ & $0.09^{*}$ & $1.27^{*}$ & $0.14^{*}$ & 1.11 \\
\hline Ethnicity & 0.00 & 1.00 & -0.00 & 0.96 & $0.01^{*}$ & $1.02^{*}$ & -0.00 & 0.93 \\
\hline Visitation by a health worker & 0.08 & 1.66 & -0.02 & 0.79 & $0.16^{*}$ & $2.01^{*}$ & 0.00 & 1.05 \\
\hline Visitation to a health facility & 0.07 & 1.34 & 0.07 & 1.17 & $0.13^{*}$ & $1.73^{*}$ & $0.18^{*}$ & $1.93^{*}$ \\
\hline Infrequent sex & 0.03 & 1.11 & 0.10 & 1.37 & $0.06^{*}$ & $1.45^{*}$ & $0.09^{*}$ & $1.54^{*}$ \\
\hline Infecundity/Subfecundity & -0.49 & - & - & - & $-0.09^{*}$ & $0.53^{*}$ & $-0.19^{*}$ & $0.37^{*}$ \\
\hline Postpartum amenorrhea & -0.19 & 0.35 & 0.23 & - & $0.11^{*}$ & $1.82^{*}$ & $0.34^{*}$ & $14.8^{*}$ \\
\hline Opposition to use & $-0.91^{*}$ & - & 0.68 & - & $-0.3 I^{*}$ & $0.31^{*}$ & $-0.49^{*}$ & 0.62 \\
\hline Cost of contraceptives & 0.26 & 5.70 & -0.22 & 0.26 & $0.13^{*}$ & $1.89^{*}$ & $0.18^{*}$ & $2.53^{*}$ \\
\hline Lack of access to contraception & -0.53 & - & - & - & $0.12^{*}$ & $2.01^{*}$ & 0.20 & 2.29 \\
\hline Fear of side effects & -0.01 & 0.88 & -0.16 & $0.46^{*}$ & -0.00 & 1.01 & -0.05 & $0.76^{*}$ \\
\hline
\end{tabular}

${ }^{*}$ Significant at $5 \%$ level of significance $(P>|t|)$ 


\section{Discussion and Conclusion}

The present study employed two statistical techniques, namely, the statistical neural network and logit models to examine the effects of selected biological and social factors on the intention to use contraception among never married and ever married women in Ghana and Nigeria respectively. On the whole, the SNN model identified more biosocial factors affecting the intention to use contraception than does the logit model. This is made possible because of the ability of the SNN model to do variable separation in the hidden unit. The more the number of hidden neurons, the better the variable separation. Also, this will lead to the output variable getting closer to the original variable. This is evidenced by the reduced error. Even though the intention to use contraception is higher in Ghana than in Nigeria, the biosocial factors that impact on intention to use contraception are more in Nigeria than in Ghana. Also, the level of effect of the biosocial factors on the intention to use contraception was found to be higher using the SNN model than with the logit model.

***The findings of this study have underscored the fact that like most healthrelated behaviours, the intention to use contraception in Ghana and Nigeria is influenced by a combination of several biological and social factors. Thus, the study's findings have shown that the influence of the biosocial factors that affect contraception use does not only differ in the number of variables that are relevant in particular contexts, but also in the magnitude of the effects of the particular variables identified by the two statistical models. However, the study also found that there are similarities that transcend geographical and cultural contexts in terms of the biosocial factors that affect the intention to use contraception in the two countries regardless of marital status. Formal educational attainment, exposure to the media, visitation to a health facility, infrequent sex, and the condition of postpartum amenorrhea all impacted intention to use contraception significantly and positively in both countries. Moreover, the study also found that the intention to use contraception in both countries is affected significantly and negatively by the number of living children, desire for more children, and the condition of infecundity/ subfecundity.

The finding about the positive effect formal education has on the intention to use contraception in both Ghana and Nigeria is consistent with several existing studies in different contexts (e.g. Mason, 1986; Vavrus \& Larsen, 2003; Singh, 1994). All these studies have invariably observed that women acquire more information about their bodies and are more able to process that information to their advantage when they are able to obtain more education. In fact, in their study, Ainsworth et al. (1996) noted that education more often than not leads to women marrying late, as well increased use of contraceptives, and subsequently low fertility.

The finding about the positive effect that exposure to the media has for intention to use contraception is equally understandable heuristically and corroborate several studies on current use of contraception (e.g. Longwe et al., 2012; Rasooly et al., 2015; Okezie et al., 2010; 
Cheng 20II; Sharma et al., 20II). Within the context of developing countries like Ghana and Nigeria, the mass media have not only become a major source of information for the majority of the people, but also a major tool in the campaign by governments to implement their population policies, especially, family planning policies. The use of mobile cinemas and availability of cheap transistor radios in far-flung corners of many developing countries attest to the important role the mass media play in spreading family planning messages.

The desire for more children in both countries was the only factor that significantly and negatively affected the intention to use contraception. This is a similar report from the works of Kabagenyi, Nankinga, and Rutaremwa ${ }^{3}$, when they found that women who perceived their husbands to want more children and those who did not know their husbands' desired number of children were less likely to use contraception. This finding and that of the number of living children, postpartum amenorrhea, infrequent sexual intercourse, lack of access to contraception and opposition to the use of contraception which showed negative relationships with intention to use contraception do not only corroborate existing studies on the subject, but also make sense heuristically. In other words, these findings have shown that the family planning decisions women make are rational in nature. In conclusion, the present study has highlighted the fact that

3 This is an online document obtained from http://iussp.org/sites/default/files/event call for papers/Perceived\%20Partners\%E2\%80\% the decisions women make in Ghana and Nigeria to either use or not use contraception is a rational one within the context of the juxtaposition of modernising and traditional forces as far as most African societies are concerned. While modernising forces such as formal education and the mass media are exerting downward pressure on fertility through encouraging the use of contraception, the inertia of the past is manifest in the persistence of traditions through cultural and religious beliefs and practices such as opposition to the use of contraception in mostly pro-natalist societies.

\section{Limitations of the study}

There are two major problems of the current study which limit the utility of its findings. Firstly, there were too many missing observations in the many variables we included in the model tested in the study. Problems with missing data are enormous and can cause serious problems. Most statistical procedures automatically eliminate cases with missing data, in fact they can eliminate entire cases whenever they encounter missing data in any variable included in the analysis. Also, the analysis might run but the results may not be statistically significant because of the presence of missing data. In addition, results may be misleading if the cases analyzed are not a random sample of all cases. Missing data can also lead to misleading results by introducing bias. Whenever segments of the target

99\%20Desire\%20for\%20More\%20Children\%2 Oand\%20Modern\%20Contraceptive\%20use.p $\underline{\mathrm{df}}$ 
population do not respond, they become under-represented in the data. In this situation, one ends up not analyzing what is intended to be measure. Secondly, the analysis for Ghana is based on the 2008 Ghana Demographic and Health Survey data. This is a limitation in the face of the release of the 2014 DHS data for Ghana notwithstanding the fact that at the time of the analysis the most recent data was not available.

\section{Acknowledgement}

The authors acknowledge the permission granted to them by MEASURE DHS for the release of the datasets used in this study.

\section{References}

Abdulla, S. 2014. Religious Affiliation and Contraceptive use in Kenya. Master of Arts Thesis in Demography and Population Studies, University of Witwatersrand, Johannesburg, South Africa.

Agha, S. 2010. Intentions to use contraceptives in Pakistan: implications for behavior change campaigns. BMC Public Health, IO(I): 450.

Ainsworth, M., Beegle, K. \& Nyamete, A. 1996. The impact of women's schooling on fertility and contraceptive use: a study of fourteen sub-Saharan African countries. The World Bank Economic Review, I0(I): 85-122.

Cheng, K.-W. 20II. The Effect of Contraceptive Knowledge on Fertility: The Roles of Mass Media and Social Networks. Journal of Family and Economic Issues, 32(2): 257-267.
Grace, K. 2010. Contraceptive use and intent in Guatemala. Demographic Research, 23(I2): 335-364.

Irani, L., Speizer, li. S. \& Fotso, J.C. 2014. Relationship characteristics and contraceptive use among couples in urban Kenya. Internal Perspectives on Sexual and Reproductive Health, 40(I): II-20.

Islam, M., Kane, T.T., -e-Khuda, B., Reza, M.M. \& Hossain, M.B. 1998. Determinants of Contraceptive Use among Married Teenage Women and Newlywed Couples. International Centre for Diarrhoeal Disease Research, Bangladesh.

Izale, K., Govender, I., Fina, J.-P. L. \& Tumbo, J. 20I4. Factors that influence contraceptive use amongst women in Vanga health district, Democratic Republic of Congo. African Journal of Primary Health Care \& Family Medicine, 6(I).

Kabagenyi A, Nankinga O, Rutaremwa G. Perceived Partners' Desire for More Children and Modern Contraceptive Use among Married Women in Uganda. Retrieved from: http://iussp.org/sites/default/files/event call for papers/Perceived\%20Partne rs\%E2\%80\%99\%20Desire\%20for\% 20More\%20Children\%20and\%20Mo dern\%20Contraceptive\%20use.pdf

Longwe, A., Huisman, J. \& Smits, J. 2012. Effects of knowledge, acceptance and use of contraceptives on household wealth in 26 African Countries. Retrieved

from: http://www.ru.nl/publish/pages/ 516298/nice 12109.pdf.

Mason, K.O. 1986. The status of women: conceptual and methodological issues in 
demographic studies. Sociological Forum, I: 284-300.

Nketiah-Amponsah, E., Arthur, E. \& Abuosi, A. 2012. Correlates of contraceptive use among Ghanaian women of reproductive age (I5-49 years): original research article. African Journal of Reproductive Health, 16(3): 154-169.

Odimegwu, C.O. 1999. Family Planning Attitudes and Use in Nigeria: A Factor Analysis. International Family Planning Perspectives, 25(2): 86-9l.

Okezie, C.A., Ogbe, A.O. \& Okezie, C.R. 2010. Socio-economic determinants of contraceptive use among rural women in Ikwuano Local Government Area of Abia State, Nigeria. International NGO Journal, 5(4): 74-77.

Omondi C.O. \& Ayiemba E.H.O. 2004. Contraceptive Use Dynamics among Migrant Women in Kenya. African Population Studies, I8(2): 69-90.

Palamuleni, M.E. 2013. Socio-Economic and Demographic Factors Affecting Contraceptive use in Malawi. African Journal of Reproductive Health, 17(3): 91-104.

Rasooly, M.H., Ali, M.M., Brown, N. \&

Noormal, B. 2015. Uptake and predictors of contraceptive use in Afghan women. BMC Women's Health, I5(I): 9.

Requejo, J. and Bryce, J. (20/0). Countdown to 2015 decade report (2000-2010) with country profiles: Taking stock of maternal, newborn and child survival. Geneva, Switzerland: World Health Organisation.

Rustagi, N., Taneja, D.K., Kaur, R. \& Ingle, G.K. 2010. Factors affecting Contraception among Women in a
Minority Community in Delhi: A Qualitative Study. Health and Population: Perspectives and Issues, 33(I): 10-15.

Sedgh, G., Hussain, R., Bankole, A. \& Singh, S. 2007. Women with an Unmet Need for Contraception in Developing Countries and Their Reasons for Not Using a Method. Occasional Report, New York: Guttmacher Institute.

Sedgh, G., Singh, S. \& Hussain, R. 2014. Intended and unintended pregnancies worldwide in 2012 and recent trends. Studies in Family Planning, 45(3): 30I$3 \mid 4$.

Sharma, S.K., Pratap K.C.N. \& Ghimire, D.R. 20II. Ethnic differentials of the impact of the Family Planning Program on contraceptive use in Nepal. Demographic Research, 25(27), 837868.

Singh, R.D. 1994. Fertility-mortality variation across LDCs: women's education, labour force participation and contraceptive use. KYLOS, .47(2): 209-229.

SPSS White Paper. Missing data:the hidden problem. Retrieved from https://www.bauer.uh.edu/jhess/2.pdf.

Stanton C, Lawn JE, Rahman H, Wilczynska-Ketende K, Hill K. (2006) Stillbirth rates: delivering estimates in I 90 countries. Lancet 367: |487-| 494. Tekelab, T., Sufa, A. \& Wirtu, D. 2015. Factors Affecting Intention to Use Long Acting and Permanent Contraceptive Methods among Married Women of Reproductive Age Groups in Western Ethiopia: A Community Based Cross Sectional Study. Family Medicine and Medical Science Research, 4(I): I-5. 
African Population Studies Vol. 29, No. 2, Supplement, 2015

The World Bank. 2015. Maternal mortality ratio (modelled estimate, per 100,000

United Nations. 2013. World live births) Data Table. Available at: http://data.worldbank.org/indicator/SH STA.MMRT.

Udomboso, C.G. 2014. On the Level of Precision of An Alternative Heterogeneous Model of the Statistical Neural Network. Ph.D. Thesis, Department of Statistics, University of Ibadan.

UNICEF (2009) State of the World's contraceptive patterns $20 \mathrm{I} 3$.

United Nations (2009). The Millennium Development Goals Report 2009. New York: United Nations Department of Economic and Social Affairs.

Vavrus, F. \& Larsen, U. 2003. Girls' education and fertility transition: an analysis of recent trends in Tanzania and Uganda. Economic Development and Cultural Change, 5I (4): 945-76.

Children 2010. New York: UNICEF. 